\title{
E4An Ultrastructural Study by Transmission Electron Microscope of Exocrine Pancreatic Cells in Diabetic Rats Treated with Herbal Combination
}

\author{
Maysaa Adil Hadi
}

Received 5/12/2018, Accepted 23/4/2019, Published 18/12/2019

This work is licensed under a Creative Commons Attribution 4.0 International License.

\begin{abstract}
:
The current study was designed to investigate the alterations in the ultrastructure of orgenelles and cellular activity of exocrine pancreatic acini of experimentally induced-diabetic rats and to assess the usefulness of herbal combination supplementation in improving the ultrastructure and cellular activity of exocrine pancreas. The number of albino male rats used were 24 which divided into equally 4 groups; group I: control group, group II: alloxan-induced diabetes mellitus (single intraperitoneal dose of alloxan 120 $\mathrm{mg} / \mathrm{kg}$ for 3 days), group III: herbal combination treatment composed from the extracts of fenugreek seeds (Trigonella foenum-graecum), black cumin (Nigella sativa) seeds, rhizomes of ginger (Zingiber officinale), leaves of olive (Olea europeae), and seeds of ash (Fraxinus ssp). Each rat given $2.5 \mathrm{ml}(0.5 \mathrm{ml}$ from each five mixed plant extracts used) for 2 months. group IV: diabetes was induced as group II and treated with herbal combination as group III for 2 months. The processing for investigating by transmission electron microscopy were carried out for all pancreata taken from all groups. There was significant reduction $(\mathrm{p}<0.05)$ in mean of FBG levels in diabetic rats treated with herbal combination (group IV) as compared to diabetic control and could revert FBG to normal value compared to negative control The results of examination of semithin and ultrathin sections in diabetic rats revealed many degenerative changes in the exocrine pancreatic tissue in comparison to control group. These degenerative changes can be summarized as disturbances in the arrangement of pancreatic acinar cells and decreased secretory granules in addition to the vacuolation of cytoplasm and pyknotic nuclei were observed in semithin sections. Moreover, degenerated nuclei, vacuolation of cytoplasm, fragmentation of rough endoplasm reticulum and degranulation of the most pancreatic acinar cells were noticed in ultrathin sections. In contrast, the acinar cells of group administrated with herbal combination only had normal ultrastructure, cellular activity, and nuclei, well-developed rough endoplasmic reticulum with abundant zymogen granules. Also, most of the acinar cells retrieved their normal ultrastructure and cellular activity in diabetic group treated with herbal combination and herbal combination could decrease most of the degenerative changes caused by alloxan-induced diabetes. In conclusion, the daily supplementation with this herbal combination to diabetic rat for 2 months could achieving promising effects due to its cytoprotective influence and showed the ability to decreased degenerative damage in the ultrastructure and cellular activity of exocrine pancreatic acini in type 2 diabetic rats.
\end{abstract}

Key word: Diabetes, Exocrine Pancreas, Herbal Combination, Transmission Electron Microscope, Ultrastructure.

\section{Introduction:}

The predominance of diabetes mellitus type- 2 has raised throughout the last 20 years, a fact driven by the raised predominance of obesity, the main risk factor for diabetes mellitus. In the Arab world, the diabetes are specifically surprising as the count of diabetic patients is projected to enlarge by $96.2 \%$ in 2035 (1).

Diabetes is a complicated syndrome characterized by hyperglycemia causes different metabolic malfunction which evident distinctive long-term

Department of Biology, College of Sciences, University of Babylon, Iraq.

E-mail: $\underline{\text { mysadil2015@gmail.com }}$ complications as several microvascular diseases, involving diabetic neuropathy, nephropathy, and retinopathy (2).

Pancreas is organ of a doubled-entity, composed of an endocrine and an exocrine component, interact in a reciprocal manner to made system whose function is related for homeostasis of nutrients, absorption, and digestion. Therefore, it is not startling that disturbance of the endocrine part of pancreas also influence the exocrine part and vice versa. However, the influence of diabetes in pancreatic exocrine function is less known (3). Although the previous data are quite restricted to 
study regeneration of $\beta$-cell which can take place in diabetes (4). Various models of regeneration in diabetes have developed and substantial regeneration of both endocrine and exocrine pancreas have been noted in many animal models (5). Although few researchers have reported the disturbed function of the exocrine pancreas in diabetic patients (6), little attention has been given to study effect of diabetes in ultrastructure of exocrine pancreas. Therefore, it would be of interest to examine the regeneration of exocrine acinar cell in diabetes mellitus.

The efficient management of diabetes requires continuous control to blood sugar level to minimize the risks of diabetic complications (7). Unfortunately, complete therapy for DM and its complications has not been established (8). Thus, natural and therapeutic antioxidants are one of the strategies for diabetic remedy. Although there are various categories of antidiabetic drugs, these drugs possibly possess significant side effects or are very expensive (9). Herbal medicine is one of the healing methods in the therapy of diabetes. It is regarded to have fewer side effects and less toxic than synthetic ones (10).

Among widely used herbs by diabetic patients is fenugreek (Trigonella foenum graecum) (family: Leguminosae). The seeds were commonly used as a spice and have anti-diabetic, anticarcinogenic, hypocholesterolemic, and antioxidant activities (11). Fenugreek possessing several bioactive components including 4-hydroxyisoleucine, flavonoids, coumarins trigonelline, saponins, (12), and diosgenin (13). Second most commonly used herb is black cumin seeds (Nigella sativa) (family: Ranunculaceae) utilized in traditional systems for many diseases. The efficacy of essential oil, seed oil, and its principal constituent thymoquinone (TQ) have examined (14). Composition of $N$. sativa seeds shows it comprises of numerous bioactive compounds such as thymoquinone, alkaloids, flavonoids, $\alpha$-hederin, antioxidants, and fatty acids. These constituents have multiple medicinal characteristics like anti-diabetic $(2,14)$, anti-cancer, anti-inflammatory, anti-dyslipidemia, antihypertension, and antioxidant activities (14).

Moreover, Ginger (Zingiber officinale Roscoe) (family: Zingiberaceae) is one of a perennial herbs. Its rhizomes are extensively used in conventional system of medicine as a flavoring agent and spice for treatment of throat, cold, cough, and chest infections (15). Ginger had antihypertensive (16) and antioxidant influences (17). Moreover, the influences of ginger on diabetes (type 2) and/or metabolic syndrome were assessed (18).

Multiple investigations have been focused on the composition of olive (Olea europaea) (family:
Oleaceae) leaves which contain an elevated concentration of phenolic compounds; particularly oleuropein (19) which confer benefits to the human health and associated to antioxidant (20).

Furthermore, Ash (Fraxinus spp.) (family: Oleaceae) was discovered in the United States (21). The seeds, bark, leaves, and fruits of the genus Fraxinus have been greatly consumed in folk medicine against a multiple of diseases. The genus Fraxinus includes a broad group of phytochemicals, mainly secoiridoid glucosides (22). An extract of Fraxinus fruits/seeds has been exhibited to cause a significant decrease in glycemia, triglyceridemia in addition to pressure of blood in several animal models of obesity, hypertension, and diabetes (23).

Scientific basis for using mixed formulations which including blood sugar decreasing herbs commonly used for diabetes treatment. Reasoning behind such formulations is supplied by contemporary research (24). Therefore, this study have aimed to investigate the ultrastructure features and alteration of cellular activity of the exocrine pancreas in alloxan-induced diabetic rats by using transmission electron microscope and to what extent herbal combination of five extracts prevents the pathological and ultrastructural changes occurred in diabetic exocrine pancreatic acini.

\section{Materials and Methods: \\ Plants extract preparation}

The plants that utilized in these experiments were bought from a local markets of herbs in Hilla city/ Babylon Province/ Iraq, besides olive leaves were gathered from Babylon University gardens. The parts of plants utilized in this study were seeds of fenugreek (Trigonella foenum-graecum), seeds of black cumin (Nigella sativa), rhizomes of ginger (Zingiber officinale), leaves of olive (Olea europeae), and seeds of ash (Fraxinus ssp). Olive leaves were desiccated in dark and all plants materials were transmitted into finely ground material $(31,32,33)$. The plants were classified by Plant Herbarium/College of Science/Dept. of Biology/ University of Babylon.

The 20\% methanolic extracts were prepared according to Sato et al. (25). The powder of each plants homogenize with mixture of solvent (methanol: distal water) $(20: 80 \mathrm{vlv})$ in blender for 30 disconnected minutes, the mixture are infiltrated and dried in oven at $45{ }^{\circ} \mathrm{C}$ for 24 hours, the dried extract store in dark container. The extract of each five plants prepared alone according to the body weight of rat (concentrations of extracts graded from $10-100 \mathrm{mg} / \mathrm{kg}$ body weight) and then equal amount $(0.5 \mathrm{ml})$ of each extract was taken and mixed together to prepare herbal combination. 


\section{Induction of diabetes}

The study included 24 adult albino male rats with an average weight of 200-250 gm. Separated cages were used for the breeding of rats in the animal house in the University of Babylon and controlled by appropriate conditions of light, temperature, and humidity and provided with laboratory diet and water ad libitum. In order to develop experimental diabetes type 2 (T2DM), rats were fasted overnight and injection a freshly prepared solution of alloxan monohydrate $\mathrm{BDH}$ Chemical/ England) which dissolved in $0.5 \mathrm{ml} 0.9 \%$ $\mathrm{NaCl}$ immediately (3 doses of $120 \mathrm{mg} / \mathrm{kg}$ body weight, one dose each 24 hours). Level of fasting blood glucose (FBG) of fasting rats were assessed every week by utilizing the glucometer (Rosmax/ Germany) and rats had fasting blood glucose $>200$ $\mathrm{mg} / \mathrm{dL}$ were considered as diabetic rats and utilized for the next experiments. Following a week's time after the development of diabetes, herbal combination treatment was initiated $(26,27,28)$. Albino male rats were distributed in random manner into four groups ( $\mathrm{n}=6$ each group) as follows:

Group I: control group in which rats treated with $0.9 \% \mathrm{NaCl}$.

Group II: alloxan-diabetic rats were not treated and used as a diabetic control group.

Group III: Herbal combination treatment for 2 months.

Group IV: diabetic rats were administrated with herbal combination for 2 months.

When the period of the experiments was completed, the animals were sacrificed, pancreas were taken and fixed in glutaraldehyde-containing phosphate buffer for electron microscope examination.

\section{Transmission Electron Microscopy Preparations}

The pancreas from experimental animals and controls were cut into small pieces of about $2 \mathrm{~mm}^{3}$, fixed in glutaraldehyde $2.5 \%$ which diluted by phosphate buffer that had $\mathrm{pH} 7.4$ for 4 hour in $4^{\circ} \mathrm{C}$ and post-fixed in an $1 \%$ osmium tetroxide solution for $1 \mathrm{~h}$. After fixation, the specimens were dehydrated and embedded in Araldite. Semithin and ultrathin sections of pancreas were cut using ultramicrotome (Reichert-Jung, Germany) by using glass Knife which made by Knife Maker (LKB, Reichert-Jung), then the sections placed on copper grids. The prepared semithin sections $(0.5-1 \mu)$ were stained with methylene blue while the prepared ultrathin sections $(60-90 \mathrm{~nm})$ were doubly stained with uranyl acetate and lead citrate $(29,30)$. A sections were examined and photographed under transmission electron microscope (Philips CM-10, Germany). The preparation, examination, and imaging of sections were done in the Electron Microscope Unit / College of Medicine/ Al-Nahrain University/ Iraq.

\section{Results:}

\section{Fasting blood glucose}

In diabetic group (group II), there was significant increase $(\mathrm{p}<0.05)$ in FBG levels $(471 \pm$ $37.98) \mathrm{mg} / \mathrm{dL}$ as compared to negative control (group I) $(124 \pm 4.219) \mathrm{mg} / \mathrm{dL}$. Furthermore, there was nonsignificant decrease in group III as compared to negative control while this group had significant reduction in mean of FBG level (79.66 4.168) $\mathrm{mg} / \mathrm{dL}$ as compared to diabetic control. Group IV showed significant reduction $(\mathrm{p}<0.05)$ in mean of FBG levels as compared to diabetic control and could revert FBG to normal value in this groups compared to negative control as shown in Fig.1.

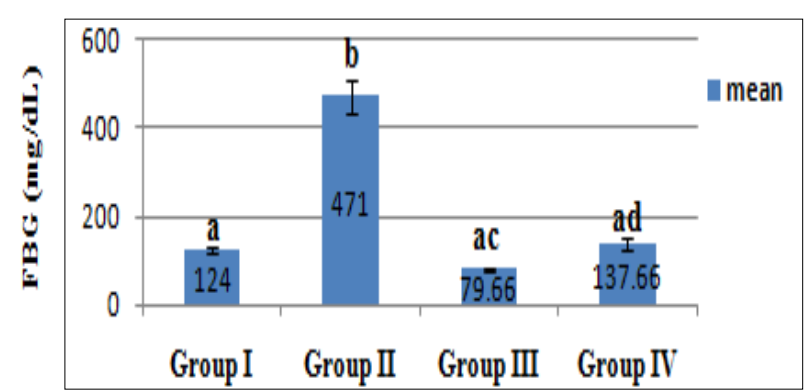

Figure 1. Level of fasting blood glucose in treated groups. Different letters refer to significance at $p<0.05$.

\section{Ultrastructural study \\ Group I (control group):}

The examination of stained semithin sections of pancreas under light microscope which showed the lobules of pancreas divide by thin interlobular septa. The exocrine tissue were organized as acini closely packed with very little connective tissue in between. The apical cytoplasm of pyramidal acinar cells had full with secretory zymogen granules and basal oval or rounded nuclei, having very small acinar lumen. Interlobular ducts and normal islets of Langerhans were also seen (Fig. 2A and B).

Similarly, ultrastructure of exocrine pancreas from control animals presented a normal ultrastructure of acinar and centroacinar cells from electron microscope examination. The acinar cells contained basal oval nuclei with prominent nucleoli, their cytoplasm full with nemerousl secretory zymogen granules of high-electron density scattered in the apical cytoplasm, and well-developed rough endoplasmic reticulum (rER) (Fig. 3). 

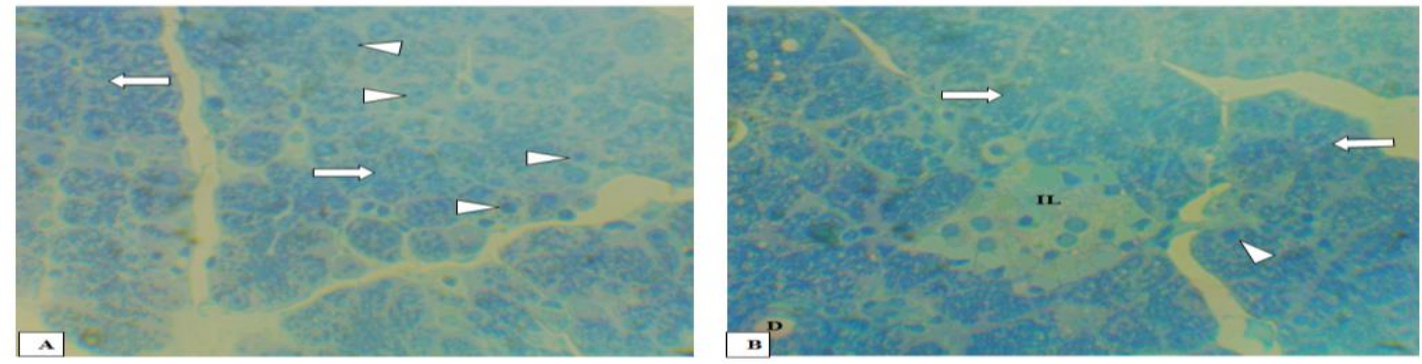

Figure 2. Photomicrographs of a semithin section of pancreas of the control group revealing normal structure of pancreatic lobules. Pancreatic acinar cells had pyramidal shape with basal oval nuclei (arrowhead) and the cytoplasm filled with abundant secretory granules $(\vec{C})$. Intralobular ducts (D) and normal islets of Langerhans (IL) are also noticed. Methylene blue, 400X.
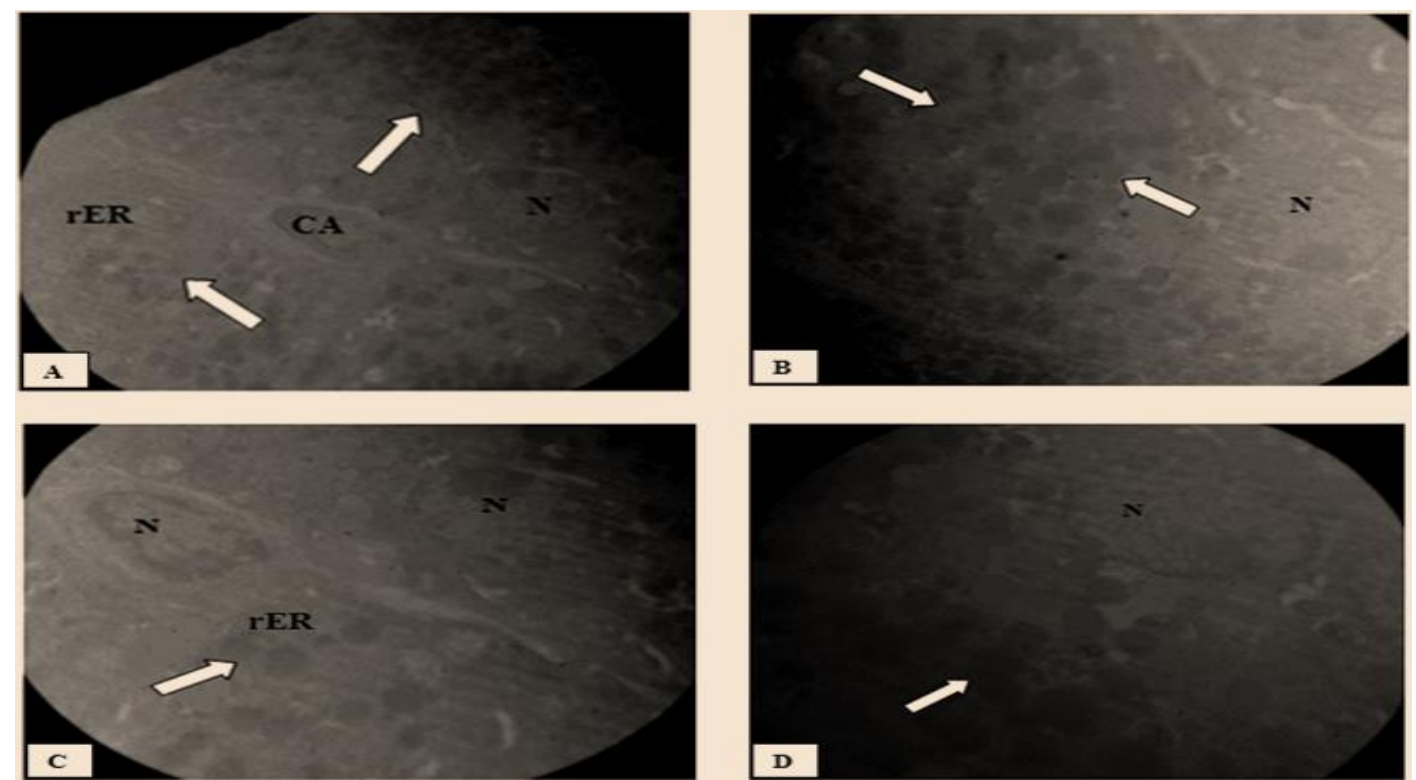

Figure 3. Transmission electron micrographs of pancreatic acinar cells of the control group revealing normal acinar cells having basal oval euchromatic nuclei $(\mathrm{N})$ with prominent nucleoli. The cytoplasm includes well-developed rough endoplasmic reticulum (rER) with numerous highelectron density secretory granules $(\Rightarrow$ th The centroacinar cells $(\mathrm{CA})$ were observed normal. Uranyl acetate and lead citrate. Magnification power A-4600X, B- 6000X, C-7900X, and D-13500X.

\section{Group II (alloxan group)}

Examination of the semi-thin sections of the pancreas from diabetic rats revealed many degenerative changes summarized in acinar pattern structure disturbance, shrinkage of cytoplasm and the cytoplasm of most acinar cells contains numerous small vacuoles, pyknotic nuclei and devoid from zymogen granules, whereas other acinar cells had a little secretory granules and small condensed nuclei. There was decreasing in the number of islets of Langerhans (Fig. 4).

Transmission electron microscopic investigation of the pancreas from group II appeared presence of a few acinar cells have nearly normal rounded euchromatic nuclei compared to the control group although most of the acinar cells have degenerated nuclei characterized by pyknotic nuclei and small condensed heterochromatic with peripheral heterochromatin condensation. In addition, the cytoplasm of the most acinar cells were vacuolated with numerous electron-lucent vacuoles, and a fragmented rough endoplasmic reticulum (frER) were noticed in the most acini. Although secretory zymogen granules production and secretion were continuing in diabetic acinar cells but the number of zymogen granules had reduced in cytoplasm of most acini which had a mixture of secretory granules, most of them had an high electron-density whereas other had homogenous moderate density. Moreover, another acinar cells were degranulated and they were almost devoid of organelles (Figs. 5 and 6). 

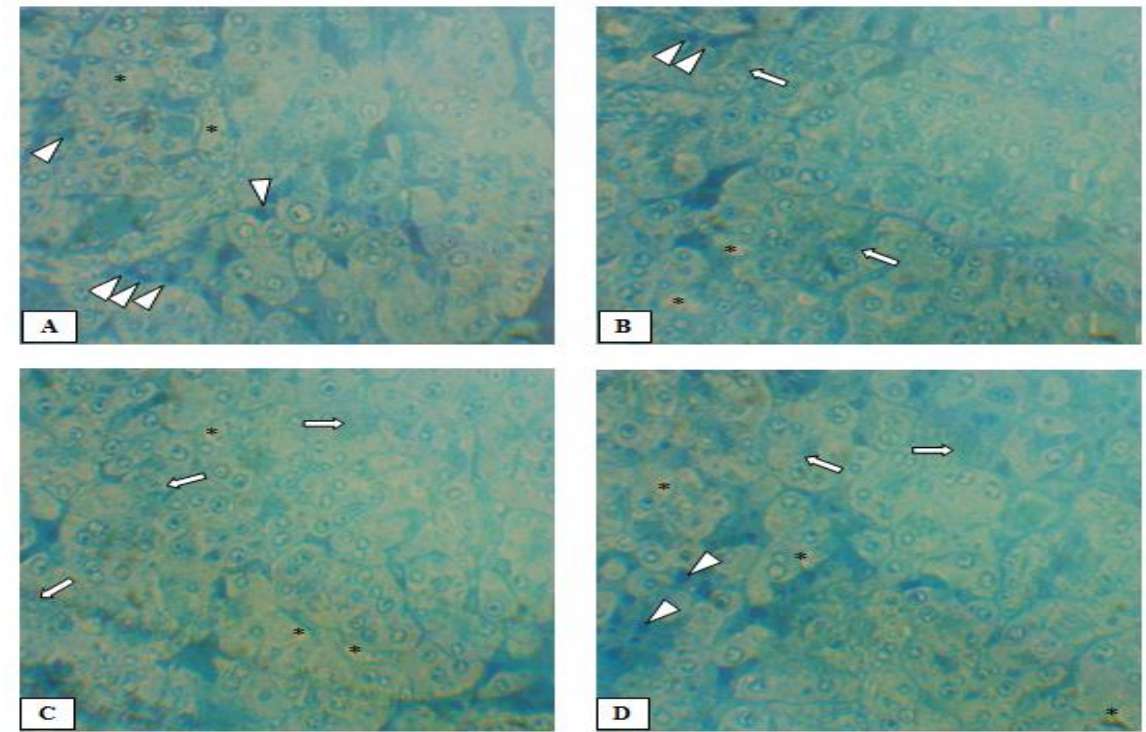

Figure 4. Photomicrographs of a semi-thin section of pancreas of the diabetic group exhibiting absence of normal distribution in the acinar pattern structure and presence of certain degenerative characteristic in most acinar cells. Majority of pancreatic acini had numerous cytoplasmic vacuoles (*), although another acini are almost devoid of vacuoles. The cytoplasm of the most pancreatic acini had lost their granules zymogen granules whereas another acini have a little secretory granules $(\Rightarrow)$. Condensed pyknotic nuclei (arrowheads) of the acinar cells are also noticed. Methylene blue, 400X.
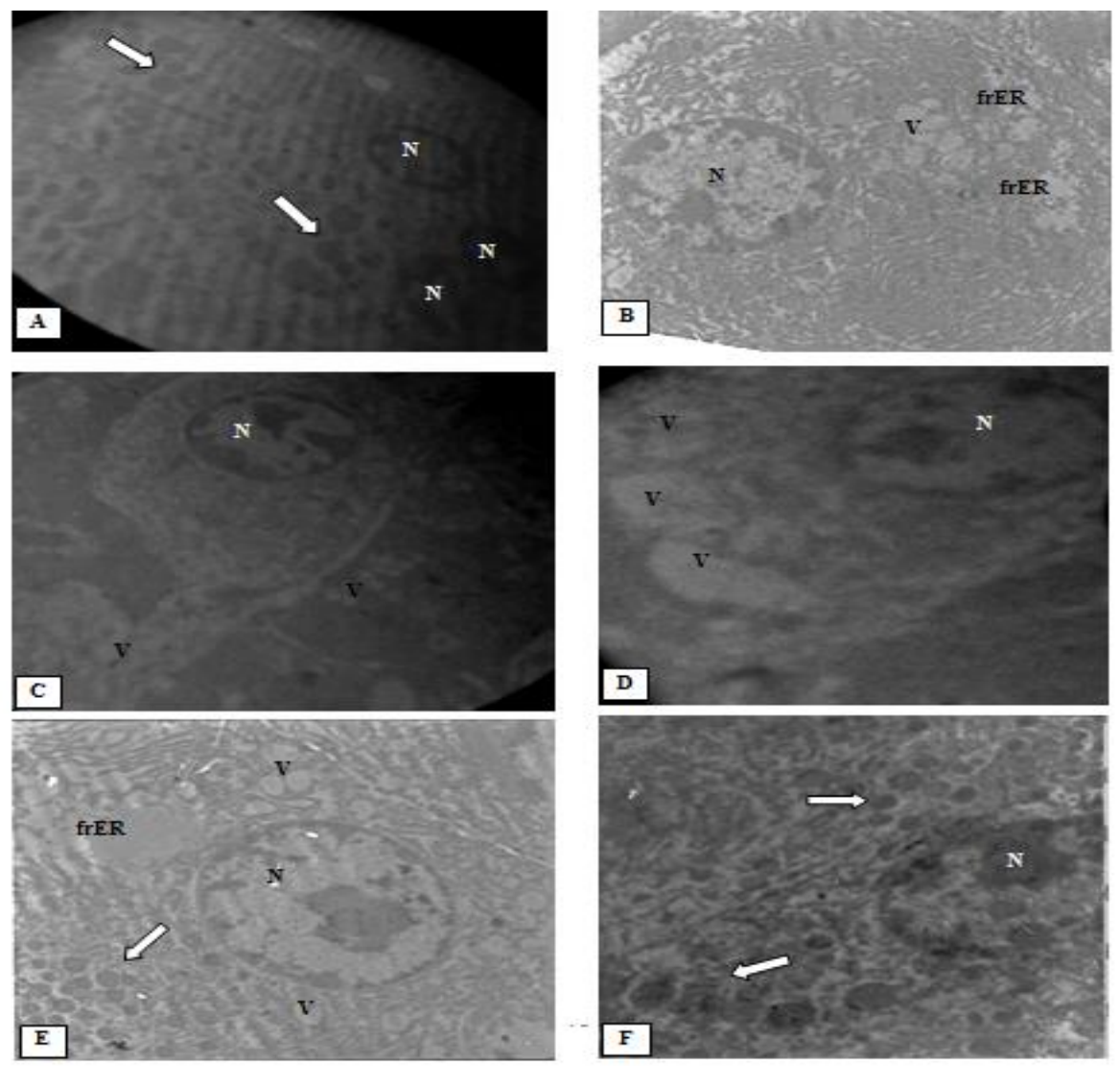

Figure 5. Transmission electron micrographs of ultrathin section of pancreatic acinar cells in diabetic rats showing: A- Most acini had degenerated nuclei with condensed heterochromatin around nuclear envelope $(N)$ and some of zymogen granules $(\Longrightarrow)$. 1100X. B- Acinar cell had degenerated nucleus $(N)$ with fragmented rough endoplasmic reticulum (frER), depletion of zymogen granules with many vacuoles in cytoplasm .4600X. C\&D- Acinar cell had degenerated $(\mathrm{N})$ nucleus with degranulation of cytoplasm with vacuoles. C- 4600X, D- 5600X. E\&F- Acinar cell had degenerated nucleus (N) with some of zymogen granules $(\Rightarrow)$ ) with vacuoles and frER. E- 5800X, F- 7900X.

Uranyl acetate and Lead citrate. 

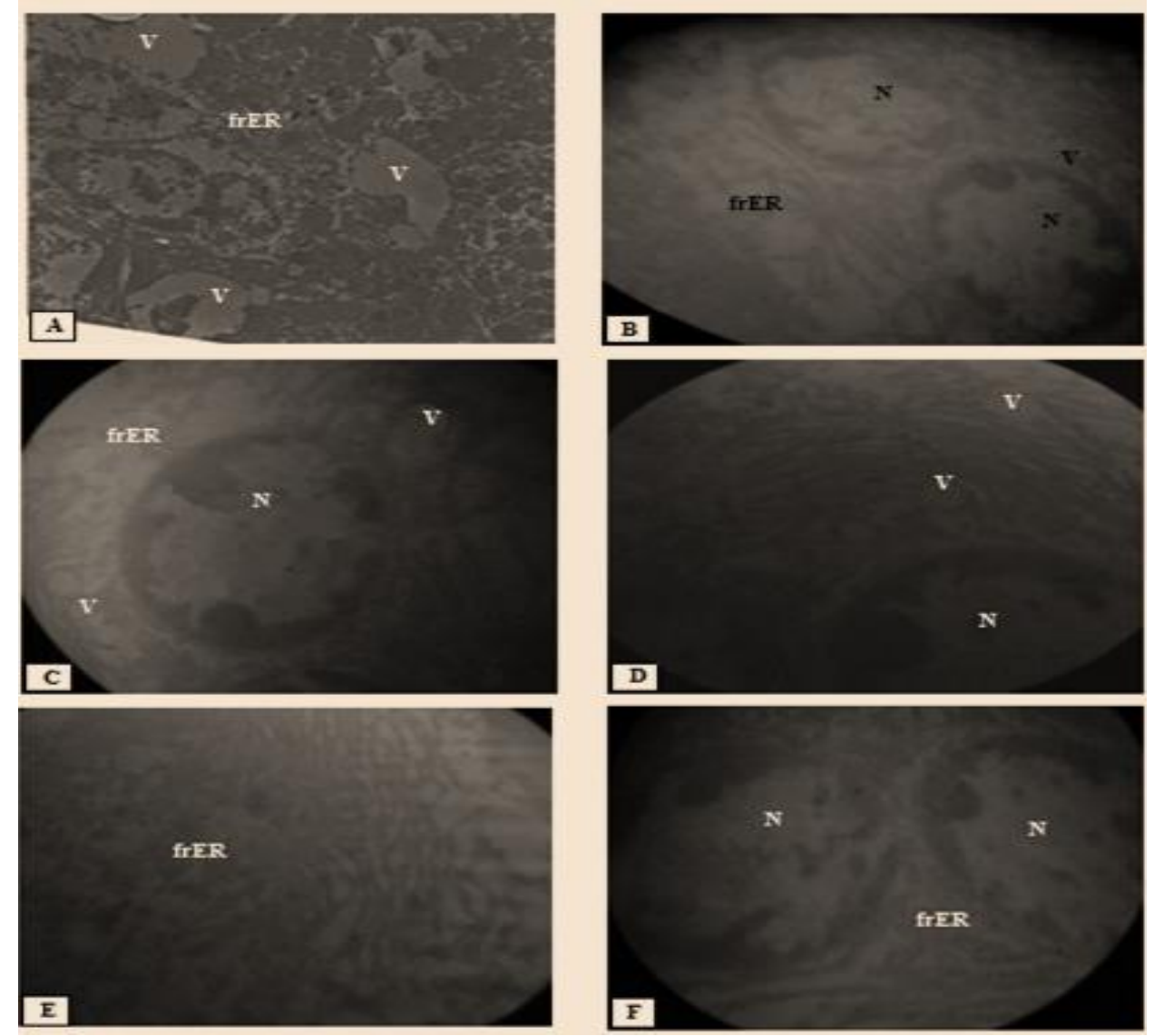

Figure 6. Transmission electron micrographs of ultrathin section of pancreatic acinar cells in diabetic rats showing:

A- Presence of degeneration in nucleus and cytoplasm, few secretory zymogen granules $(\Longrightarrow)$ and large vacuoles in cytoplasm $(V)$, fragmented rough endoplasmic reticulum (frER). 7900X.

B, C, D, E: Degranulation of acinar cells and depletion of zymogen granules, large area of cytoplasm contain frER and many vacuoles. B - 13000X, C - 25000X, D - 19000X, and E- 25000X.

F: Acinar cells had degenerated nucleus $(N)$ and fragmented rough endoplasmic reticulum (frER). 25000X.

Uranyl acetate and lead citrate.

Group III (treated with herbal combination only)

In herbal combination group, semithin section showed normal histological structure of pancreatic acini resemble control acinar cells. Most acinar cells had the regular-shaped nucleus and homogenous cytoplasm filled numerous secretory zymogen granules (Fig.7). Ultrastructurally, the nuclei showed normal and regular-shaped nucleus and homogenous cytoplasm with well developed rough endoplasmic reticulum and appearance of numerous secretory zymogen granules (Fig.8).
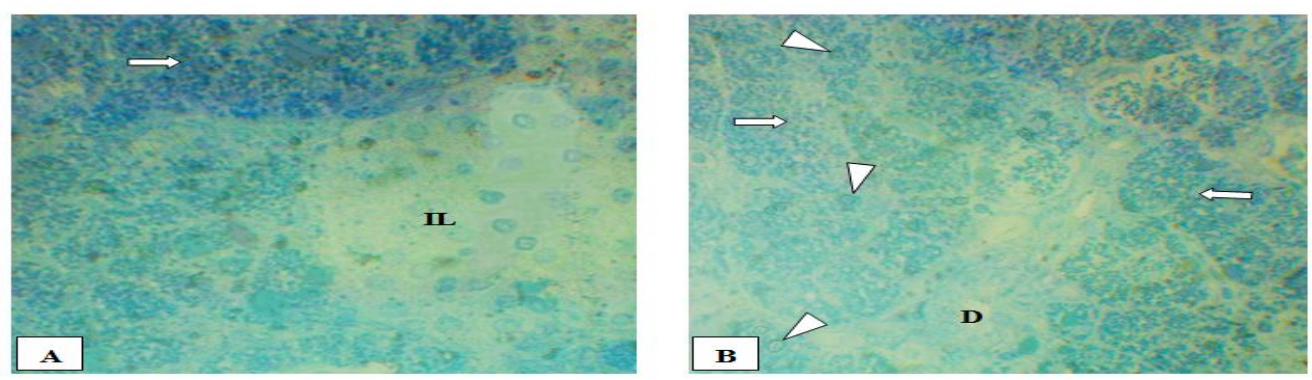

Figure 7. Photomicrographs of a semithin section of pancreas in group treated with the herbal combination showing normal cytoplasm of the most pancreatic acini filled with numerous zymogen granules $(\Rightarrow)$. Normal nuclei (arrowheads), intralobular pancreatic duct (D), normal islet of Langerhans (IL). Methylene blue, 400X. 

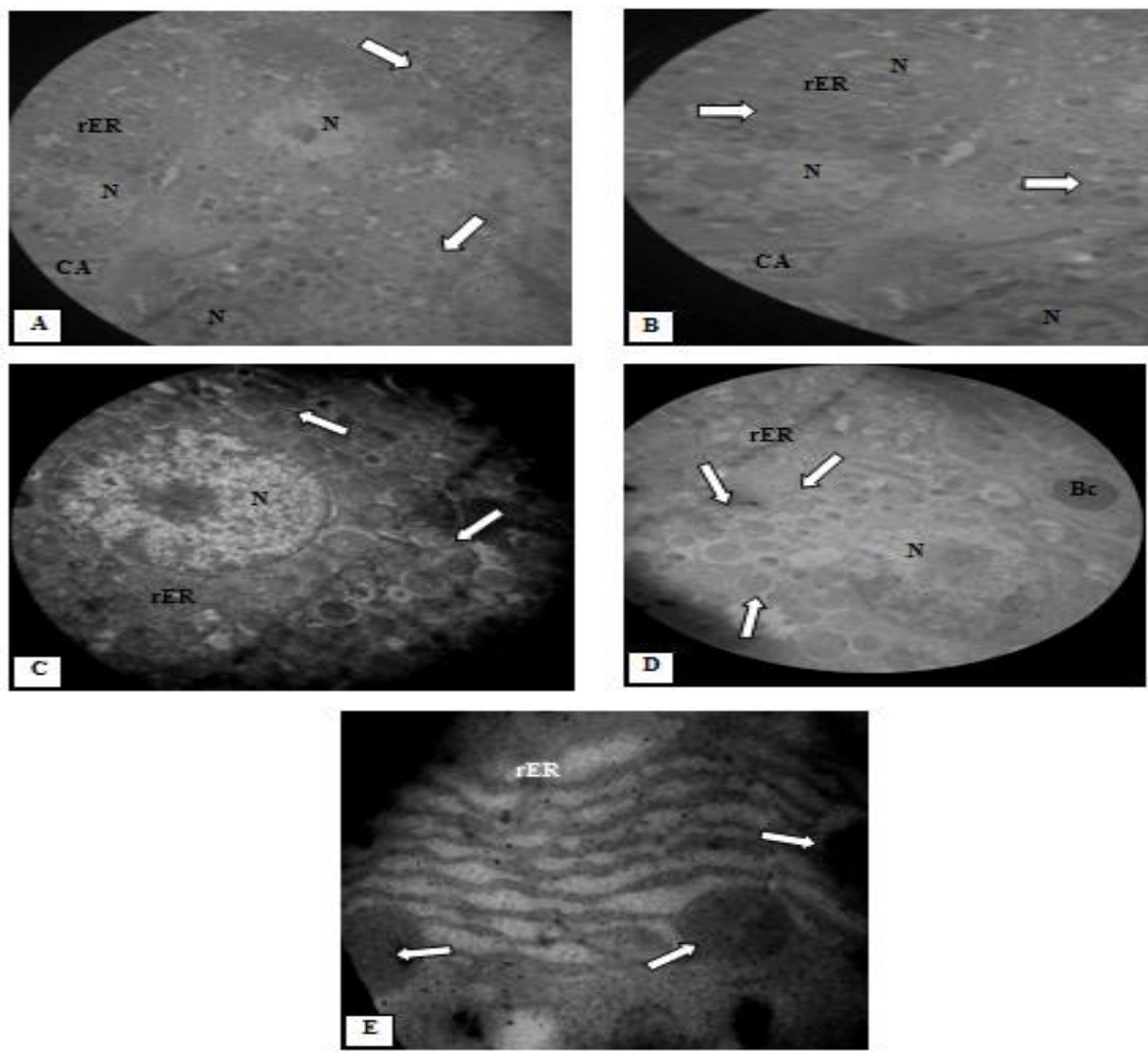

Figure 8. Transmission electron micrographs of pancreatic acinar cells in group treated with the herbal combination group showing most acinar cells had the regular-shaped nucleus (N) and homogenous cytoplasm with well developed rough endoplasmic reticulum (rER) and presence of numerous secretory zymogen granules $(\Rightarrow)$. Also, blood capillary $(B c)$ and centroacinar cells were noticed normal in sections. A-3400X, B- 6200X, C\&D-8700X and E-24000X. Uranyl acetate and lead citrate.

Group IV (received both alloxan and herbal combination)

Examination of methylene-stained semithin sections of this group exhibited regeneration of most lobules of pancreatic. Increased the number of pancreatic acinar cells which had an apical cytoplasm filled with numerous secretory zymogen granules and basal oval or regular-shaped nuclei (Fig. 9A). Little acinar cells still had pyknotic nuclei, cytoplasmic vacuoles and few or depletion of secretory zymogen granules (Fig. 9 B).

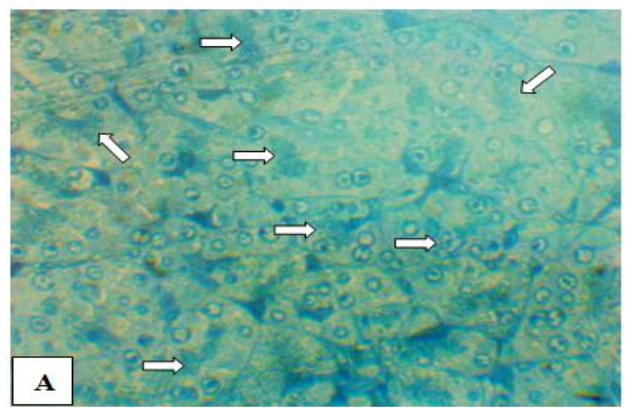

Also, examination by electron microscopic exhibited evident regeneration of degenerative changes induced by alloxan in most exocrine pancreatic acini. Most acinar cells had normal rounded euchromatic nuclei and well-developed rough endoplasmic reticulum with different stages of zymogen secretory granules synthesis graded from light-electron density to moderate or highelectron density secretory granules (Fig.10, A, B, C\&D) whereas other cells had a little secretory granules and another few cells still had electronlucent vacuoles (Fig. 10, C\&E).

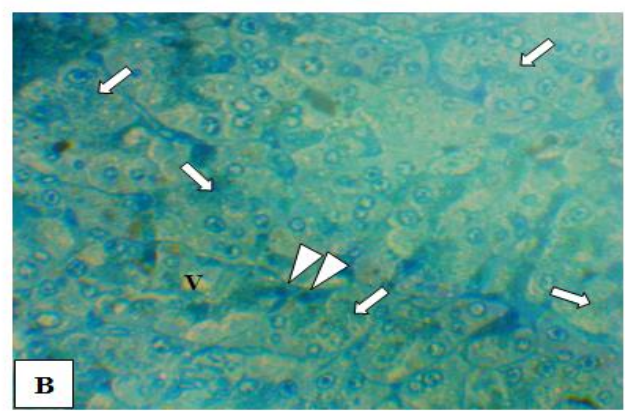

Figure 9. Photomicrographs of a semithin section of pancreas in group received both alloxan and herbal combination exhibiting regeneration in the most acinar cells. A: The cytoplasm of the most pancreatic acini filled with numerous zymogen granules $(\Rightarrow)$. B: Few acinar cells still had pyknotic nuclei (arrowheads) and cytoplasmic vacuoles (V). Methylene blue, 400X. 


\section{Discussion:}

People often seek care from multiple sources outside the formal traditional health care system. One of these sources is the usage of Alternative and Complementary Medicine including herbal medications. Diabetic patients are found 1.6 times greater likely to use Alternative and Complementary Medicine than nondiabetic patients (31). In the current study, the effectiveness of herbal combination was investigated, which composed from five of commonly used herbal medications by diabetic patients in Iraq which were seeds of fenugreek, seeds of black cumin, rhizomes of ginger, leaves of olive, and seeds of ash on ultrastructure and cellular activity of exocrine pancreatic acini in diabetic rats. As well, their ability to regeneration of both ultrastructure and cellular activity of exocrine pancreatic tissue subsequent to the induction of diabetes for the reason that documentary evidence that this herbal combination was effective in reducing levels of serum sugar and urea, enhancing insulin secretion and caused significant gain in body weight as compared with diabetic control group (28). In addition, decreasing DNA fragmentation (27) and decreasing chromosomal aberrations in diabetic rats (26)

In current study, mainly of the acinar cells in diabetic group had a pyknotic nuclei, fragmented rER, few secretory zymogen granules, and numerous electron-lucent vacuoles. A little acinar cells had cytoplasm with electron-lucent areas that were almost lacking of organelles. The cellular damage was induced by alloxan that has mechanism of action on the cell mediated by the synthesis of free radicals and the oxidized products of oxidative stress such as reactive oxygen species (32). These abnormality may result from reactive oxygen species (ROS) formation and oxidative stress and hence DNA strand fragmentation, breaks, and loss of chromosome integrity (33).
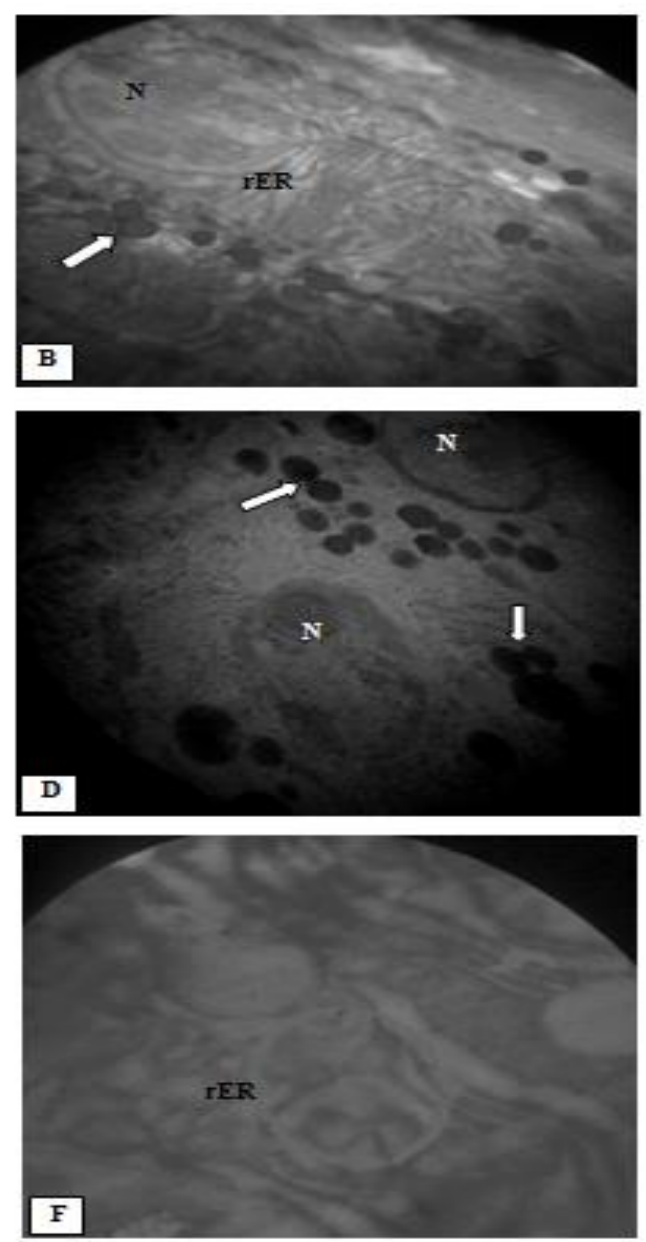

Figure 10. Transmission electron micrographs of a section of pancreatic acinar cells of group that received both alloxan and herbal combination showing: A\&B: Regeneration in both nuclei and cytoplasm of acinar cells with numerous electron-dense secretory granules $(\square$ and blood capillary (Bc), normal cytoplasm with presence of abundant and well-developed rough endoplasmic reticulum (rER), and absence of vacuoles (A, B and D). A-5800X, B-125000X. C, D\&E: Acinar cells had some secretory granules and few of electron-lucent vacuoles (V). C- 8700X, D-13000X, E-16000X. F- Acinar cell had well-developed rough endoplasmic reticulum (rER). 24000X. 


\section{Uranyl acetate and lead citrate.}

The significant increasing in FBG in diabetic group due to alloxan is best-known diabetogenic agent for its selective cytotoxicity for $\beta$ cells and have been widely utilized to induce type-I $(32,34$, $35)$ or type-II like diabetes $(27,31)$ in experimental models according to the dose and number of doses. Also, relies on the species of animal, route of administration, and nutritional status (35). The degenerative alterations in pancreatic acini in diabetic-induced rats may due to increased ROS production which are able to oxidation alteration and destruction of lipid in cellular membranes, particularly highly unsaturated fatty acids, by way of lipid peroxidation, result in suppression of the synthesis of protein and fragility of the zymogen granules (36). Particularly, production of ROS has been revealed to be influential in the etiology of diabetes by acting at the following various levels: 1) impairing uptake of glucose and pathways of insulin signaling $(37,2)$ modifying lipid metabolism and metabolic parameters $(38,3)$ immune activation and raising inflammatory response (39) and (4) Both apoptosis and necroptosis that may culminate in tissue injuries in the kidneys, heart, retina, and nervous system (40).

Moreover, degranulation of acinar cells in the current study is likely as a result of the decrease in synthesis of digestive enzymes which may be disrupted by diabetes. This result may due to secretion of pancreatic enzyme may be disrupted by diabetes because endocrine part of pancreas is strongly integrated physiologically and anatomically with the exocrine part of pancreas and modulates its function (41). The synthesis of digestive enzymes is regulated by complex of neurohormonal mechanisms that excited by nutrients in addition to brain-gut axis have role in the modulation the secretion of enzyme by pancreas (42). Also, diabetes cause defective pancreatic morphogenesis, and the absence of secretin- and cholecystokinin may illustrate the abnormal polarity and inability to secretion of zymogen granules in exocrine pancreatic cells (43). The predominance of exocrine pancreatic insufficiency in patients with diabetes mellitus type- 1 and type- 2 is $37.7 \%$ and $26.2 \%$ respectively (7). Cell growth of pancreatic acinar stimulated by insulin exerting trophic effects on the exocrine pancreas (44). These stimulatory and trophic insulin effects are lost in diabetes mellitus. Furthermore, raised levels of inhibitory islet hormones such as somatostatin (in nondiabetic subjects ranged from 43 to $97 \mathrm{pg} / \mathrm{ml}$, in non-insulindependent diabetics from 5 to $3872 \mathrm{pg} / \mathrm{ml}$ ) (45) and glucagon (chronically elevated glucose concentrations increase glucagon release by $2.5-$ to 4-fold, glucagon cell content by 2.5 - to 3 -fold, and proglucagon messenger RNA levels by 4 - to 8 -fold (46) also contribute to pancreatic exocrine insufficiency in diabetes. Further, type II diabetes human and rodent pancreas specimens show a loss of adherens junctions and desmosomes between acinar cells and islets, due to fibrosis and remodeling of the islet-acinar interface, that may result in an impaired function (6).

The degenerative alterations of the acini in current study were similar to those previous studies which recorded that the diabetes induced by alloxan result in a considerable structural damage in tissues of pancreas as disturbance in acinar pattern structure, shrinkage of most acinar cells, presence of pyknotic and vesicular nuclei,. In addition to accumulation of the heterochromatin along the nuclear envelope of the nuclei of $\beta$ cells which was proposed that these alterations may as a result of shrinkage and condensation of the nuclear material $(5,34)$. The level of antioxidant enzymes critically affects the susceptibility of different tissues to oxidative stress and is connected with the development of complications in diabetes (47). Therefore, the usage of antioxidants is considered as one of the strategies used for treat and reduce the complication in diabetic patients (48). In comparison to the synthetic drug, natural plants have lesser toxicity and some are devoid of any side effects. Numerous plant extracts are known to possess antidiabetic properties that could be used in the remedy of diabetes mellitus (49).

It was an important to note that administration of herbal combination to diabetic rats in this study had minimized numerous of degenerative alterations in acinar cells and presence of its normal nuclei, rough endoplasmic reticulum, and cytoplasm with abundant zymogen granules. This results may due to antioxidant activity of herbal combination which had been previously reported to reduce effects of diabetes and cause significant reduction in fragmentation of DNA extracted from both renal cortex and white blood cells in diabetic group which treated with the same herbal combination (27). These results due to antioxidant activities which minimize or prevent production of free radicals. Moreover, treatment with this herbal combination significantly minimized chromosomal aberrations and mitotic index in all groups of treatment and for different period (45, 60 and 75 days) (26).

Plants have many phytochemicals, which may target multiple pathways of cell signalling concurrently and may act by synergistic action. The ascribed antihyperglycemic influences of these plants are in consequence of their capability to return the pancreatic tissues function by increasing output of insulin or repress the glucose absorption by intestine (50). 
Furthermore, the active compound was effective in the restoration of impaired beta cell functions and increment the releasing of endogenous insulin from pancreatic $\beta$-cells. In addition, significant inhibition $(\mathrm{P} \leq 0.05)$ was showed in the levels of FBG in treated group as compared with diabetic control. Also, improve the utilization of glucose in the tissue and organ; as indicated by inducing regeneration of pancreas and enhancement of pancreas weight (28). Alternatively, its action may be connected to its antioxidant compounds which minimize production of free radicals and oxidative stress in diabetic group (27). Moreover, it could repress most degenerative changes took place in testes and epididymis in diabetic groups administrated with the herbal combination (51). These results confirm the herbal combination could be administrated as drug to treat diabetes type 2 patients. Furthermore, this enhancement in endocrine function of pancreas reflected the regeneration in exocrine pancreas because endocrine part of pancreas is modulates exocrine pancreas function (43).

There was no ultrastructural alterations in exocrine pancreas of rats treated with herbal combination only. This results were in accordance with (28) who revealed that treatment of normal rats with the same herbal combination for 60 days showed nonsignificant alterations in fasting blood glucose, fasting serum insulin, urea levels and pancreas /body weight ratios.

\section{Conclusion:}

The current study concluded that alloxan has a degenerative influence on the ultrastructure and cellular activity of the exocrine pancreatic acinar cells. Apparently, herbal combination has a potent capability to provide protection against pancreatic damage generated in alloxan-induced diabetic rats and has a therapeutic protective effect against diabetes. Overall, the results exhibited that the herbal combination used in this study have diverse biological actions and can be improved as a therapeutical on the basis of its hypoglycemic, antioxidant, and anti-genotoxic potential and has shown to provide meaningful protection against alloxan cytotoxicity. According to our previous and recent findings, herbal combination treatment may be innovation for both endocrine and exocrine pancreatic tissue regeneration in diabetes.

\section{Conflicts of Interest: None.}

The author has signed on animal welfare statement.

\section{References:}

1. Abuyassin B, Laher I. Diabetes epidemic sweeping the Arab world. World J Diabetes 2016; 7 (8): 165-174. 2. Abdelrazek HMA, Kilany OE, Muhammad MAA, Tag HM, Abdelazim AM. Black Seed Thymoquinone Improved Insulin Secretion, Hepatic Glycogen Storage, and Oxidative Stress in Streptozotocin Induced Diabetic Male Wistar Rats. Oxidative Medicine and Cellular Longevity 2018; 2018: 10 pages.

3. Piciucchi M, Capurso G, Archibugi L, Fave MD, Capasso M, Fave GD. Exocrine Pancreatic Insufficiency in Diabetic Patients: Prevalence, Mechanisms, and Treatment. International Journal of Endocrinology 2015; 2015: 7 pages.

4. Benthuysen JR, Carrano AC, Sander M. Advances in $b$ cell replacement and regeneration strategies for treating diabetes. J Clin Invest. 2016; 126 (10):36513660 .

5. Abban-mete G, Erdogan D, Cam M, Ozogul C, Mete E. The Effects of Epidermal Growth Factor on Pancreas in Alloxan-Diabetic Rats: An Ultrastructural Study. Journal of Endocrinology and Diabetes Mellitus 2013; 1(2): 27-32.

6. Hayden MR, Patel K, Habibi J. Attenuation of endocrine-exocrine pancreatic communi-cation in type 2 diabetes: pancreatic extracellular matrix ultrastructural abnormalities. J Cardiometab Syndr 2008;3(4): 234-243.

7. World Health Organization. Global Report on Diabetes 2016; Page:11.

8. Kim J, Choi J, Lee M, Kang K, Paik M, Jo S, et al. Immunomodulatory and Antidiabetic Effects of a New Herbal Preparation (HemoHIM) on Streptozotocin Induced Diabetic Mice. Evidence-Based Complementary and Alternative Medicine 2014; 2014: 8 pages.

9. Nasri H, Shirzad H, Baradaran A, Rafieian-kopaei M. Antioxidant plants and diabetes mellitus. Journal of Research in Medical Sciences 2015; 20 (5):491-502.

10. Sharma R, Amin H, Prajapati P. Plant kingdom Nutraceuticals for diabetes. Journal of Ayurvedic and Herbal Medicine 2016; 2(6): 224-228.

11. Aher RR, Belge SA, Kadam SR, Kharade SS, Misal AV, Yeole PT. Therapeutic Importance of Fenugreek (Trigonella foenum-graecum L.): A Review. J Plant Sci Res. 2016; 3(1): 149.

12. Vigh SZ, Cziaky Z, Sinka LT, Pribac C, Mos L, Turcus V, et al. Analysis of Phytoconstituent Profile of Fenugreek -Trigonella foenuem -graecum L. -Seed Extracts. STUDIA UBB CHEMIA 2017; 2: 145-166.

13. Szabó K, Gesztelyi R, Lampé N, Kiss R, Remenyik J, Pesti-Asbóth G, et al. Fenugreek (Trigonella foenumgraecum) Seed Flour and Diosgenin Preserve Endothelium-Dependent Arterial Relaxation in a Rat Model of Early-Stage Metabolic Syndrome. Int. J. Mol. Sci. 2018; 19: 798.

14. Srinivasan K. Cumin (Cuminum cyminum) and black cumin (Nigella sativa) seeds: traditional uses, chemical constituents, and nutraceutical effects. Food Quality and Safety 2018; 2: 1-16.

15. Sharma PK, Singh V, Ali M. Chemical Composition and Antimicrobial Activity of Fresh Rhizome 
Essential Oil of Zingiber Officinale Roscoe. Pharmacogn. J. 2016; 8 (3): 185-190.

16. Shaban MI., EL-Gahsh NFA, El-said A, El-sol H. Ginger: It's Effect on Blood Pressure among Hypertensive Patients. IOSR-JNHS 2017; 6(5): 7986.

17. Felfoul I, Borchani M, Samet-Bali O, Attia H, Ayadi MA. Effect of ginger (Zingiber officinalis) addition on fermented bovine milk: Rheological properties, sensory attributes and anti-oxidant potential. Journal of new sciences, Agriculture and Biotechnology 2017; 44 (3): 2400-2409.

18. Zhu J, Chen H, Song Z, Wang X, Sun Z. Effects of Ginger (Zingiber officinale Roscoe) on Type 2 Diabetes Mellitus and Components of the Metabolic Syndrome: A Systematic Review and Meta-Analysis of Randomized, Controlled Trials. Evidence-Based Complementary and Alternative Medicine 2018; 2018: 11 pages.

19. Goldsmith CD, Vuong QV, Sadeqzadeh E, Stathopoulos CE, Roach PD, Scarlett CJ. Phytochemical Properties and Anti-Proliferative Activity of Olea europaea L. Leaf Extracts against Pancreatic Cancer Cells. Molecules 2015; 20: 1299213004.

20. Ivanov $\mathrm{M}$, Vajic $\mathrm{U}$, Mihailovic-stanojevic $\mathrm{N}$, Miloradovic Z. Highly Potent Antioxidant Olea Europaea L. Leaf Extract Affects Carotid and Renal Haemodynamics in Experimental Hypertension: The Role of Oleuropein. EXCLI Journal 2018; 17:29-44.

21. Duan JJ, Bauer LS, van Driesche RG, Gould JR. Progress and Challenges of Protecting North American Ash Trees from the Emerald Ash Borer Using Biological Control. Forests 2018; 9: 142.

22. García-villalba R, Tomás-barberán FA, Fançaberthon P, Roller M, Zafrilla P, Issaly N. Targeted and Untargeted Metabolomics to Explore the Bioavailability of the Secoiridoids from a Seed / Fruit Extract (Fraxinus angustifolia Vahl) in Human Healthy Volunteers : A Preliminary Study. Molecules 2015; 20: 22202-22219.

23. Montó F, Arce C, Noguera MA, Ivorra MD, Flanagan $\mathrm{J}$, Roller M, et al. Action of an extract from the seeds of Fraxinus excelsior L. on metabolic disorders in hypertensive and obese animal models. Food Funct. 2014; 5: 786-796.

24. Kosta S, Tiwari A. A Fusion of Ancient Medicinal Plants with Modern Conventional Therapies on its Multifaceted Antidiabetic Properties. Pharmacologyonline 2009; 1: 64-77.

25. Sato T, Onse Y, Nagase H, Kito H. Mechanism of antimutagenicity of aquatic plant extracts against (benzo (a) yrene) in the Salmonella assay. J. Mut. Res. 1990; 241: 283-290.

26. Al-Joubori MA, Zaidan HK, Saadi AH. Evaluation of Chromosome Aberrations and Mitotic Index in Alloxan-Induced Diabetic Male Rats Treated with the Mixture of Plants Extracts Mixture, Journal of Babylon University/Pure and Applied Sciences 2014; 22 (5): 1545-1555.

27. Al-Joubori MA, Al-Saadi AH, Zaidan HK. Effect of a Mixture of Plants Extracts on Genomic DNA, Insulin Receptor, and Insulin Receptor Substrate-1
Genes in Alloxan-Induced Diabetic Male Rats. Journal of Biology, Agriculture and Healthcare 2013; 3(2):140-150.

28. Hadi MA, Zaidan HK, Al-Saadi, AH. Histopathological Changes of Pancreatic Tissues in Hyperglycemic Male Rats Treated with Mixture of Plants Extracts. International Journal of ChemTech Research 2016; 9(6): 501-513.

29. Hadi MA, Al-Kasiy KSN, Zaidan HK. Study the effect of prostaglandin $\mathrm{F}_{2} \alpha$ and watery extract of Trigonella foenum-graecum L. seeds in pancreatic cells of male albino mice. Journal of Babylon University/Pure and Applied Sciences 2007;14 (3): 161. ( in Arabic).

30. Al-Kasiy KSN, Zaidan HK, Hadi MA. Study the effect of prostaglandin $\mathrm{F}_{2} \alpha$ in ultrastructure and cellular activity of pancreas in mice. Journal of Babylon University/Pure and Applied Sciences 2007; 14 (2): 106-117. (in Arabic).

31. Ahmed JH, Mansour AA. Evaluation of the effectiveness of cinnamon, fenugreek and their combination on patients with type 2 diabetes in Basrah. MJBU 2014; 32 (1):15-21.

32. Danilova IG, Bulavintceva TS, Gette IF, Medvedeva SY, Emelyanov VV, Abidov MT. Partial recovery from alloxan-induced diabetes by sodium phthalhydrazide in rats. Biomed. Pharmacother. 2017; 95: 103-110.

33. Cinkilica N, Kiyici S, Celikler S, Vatan O, Gul O, Tuncel E, et al. Evaluation of chromosome aberrations, sister chromatid exchange and micronuclei in patients with type-1 diabetes mellitus. Mutat Res. 2009; 676 (1-2):1-4.

34. Walvekar MV, Pol SB, Sagar BK. Histopathological and ultrastructural studies of the Effect of Fenugreek Seed Extract on Pancreas of Alloxan Induced Diabetic Mice. IJPSR 2014; 5(7): 2960-2965.

35. Federiuk IF, Casey HM, Quinn MJ, Wood MD, Ward WK. Induction of type 1 diabetes mellitus in laboratory rats by use of alloxan; route of administration, pitfalls, and insulin treatment. Comp Med 2004; 54: 252-257.

36. Stevens T, Conwell DL, Zuccaro G. Pathogenesis of chronic pancreatitis: an evidence-based review of past theories and recent developments. Am J Gastroenterol. 2004; 99:2256-2270.

37. Hurrle S, Hsu WH. The etiology of oxidative stress in insulin resistance. Biomed J 2017; 40: 257-262.

38. Masuoka HC, Chalasani N. Nonalcoholic fatty liver disease: an emerging threat to obese and diabetic individuals. Ann N Y Acad Sci 2013; 1281:106-122.

39. Newsholme P, Cruzat VF, Keane KN, Carlessi R, Bittencourt PIH. Molecular mechanisms of ROS production and oxidative stress in diabetes. Biochemical Journal 2016; 473: 4527-4550.

40. Liang W, Chen M, Zheng D, He J, Song M, Mo L, et al. A novel damage mechanism: contribution of the interaction between necroptosis and ROS to high glucose-induced injury and inflammation in $\mathrm{H} 9 \mathrm{c} 2$ cardiac cells. Int. J. Mol. Med. 2017; 40, 201-208.

41. Pandiri AR. Overview of Exocrine Pancreatic Pathobiology. Toxicologic Pathology 2014; 42: $207-$ 216. 
42. Jaworek J, Nawrot-Porabka K, Leja-Szpak A, Kontturek SJ. Brain-Gut Axis in the Modulation of Pancreatic Enzyme Secretion. Journal of Physiology and Pharmacology 2010; 61(5): 523-531.

43. Naya FJ, Huang H, Qiu Y, Mutoh H, Francesco J, DeMayo FJ. Diabetes, defective pancreatic morphogenesis, and abnormal enteroendocrine differentiation in BETA2 /NeuroD-deficient mice. Genes \& Development 1997; 11:2323-2334. 44. Logsdon CD. Stimulation of pancreatic acinar cell growth by CCK. Epidermal growth factor and insulin invitro. Am J Physiol 1986; 251:487-494.

45. Ertan A, Arimura A, Akadamar K. Pancreatic immunoreactive somatostatin and diabetes mellitus. Dig Dis Sci 1984; 29:625-630.

46. Dumonteil E, Ritz-Laser B, Magnan C, Grigorescu I, Ktorza A, Philippe J. Chronic Exposure to High Glucose Concentrations Increases Proglucagon Messenger Ribonucleic Acid Levels and Glucagon Release from InR1G9 Cells. Endocrinology 1999; 140(10): 4644-4650.

47. Rasheed MN, Hasan OM, Mahmood AS. Association of Glutathione S-Transferase (GSTM1, T1) Gene
Polymorphisms with Type 2 Diabetes Mellitus (T2DM) in the Iraqi Patients. Iraqi Journal of Biotechnology 2015; 14(1): 70-76.

48. Rajendiran D, Packirisamy S, Gunasekaran K. A Review on Role of Antioxidants in Diabetes. Asian J Pharm Clin Res 2018; 11(2): 48-53.

49. Tag HM, Abdelazek, HMA, Mahoud YS, ELShenawy NS. Efficacy of Tribulus terrestris extract and metformin on fertility indices and oxidative stress of testicular tissue in streptozotocin-induced diabetic male rats. African Journal of Pharmacy and Pharmacology 2015; 9 (48): 1088-1098.

50. Ansarullah, Bharucha B, Patel V, Ramachandran AV. Improved Glucoregulation, Insulin Resistance and Leptin Levels by a Polyherbal Drug in High Fat Diet and Low Dose Streptozotocin Type 2 Diabetes Model. Diabetologia Croatica 2012; 41 (1): 3-15.

51. Hadi MA, Zaidan HK, Natah TM, Al-Saadi AH. Protective Effect of Plants Extracts Mixture on Sperm Abnormalities, Testicular and Epididymal Tissues in Diabetic Male Rats. Journal of Natural Sciences Research 2013; 3(9): 28-37.

\title{
دراسة التركيب المستدق بالمجهر الاكتروني الناقذ لخلايا البنكرياس خارجية الافراز في الجرذان المصابة بالسكري والمعاملة بخلطة عشبية النيانية
}

\author{
ميساء عادل هادي
}

قسم علوم الحياة، كلية العلوم، جامعة بابل، بابل، العراق.

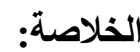

ان هدف الدراسة الحالية هو التحري عن التغييرات في التركيب المستدق للعضيات الخلوية و الفعالية الخلوية لاسناخ (عنيبات) البنكرياس

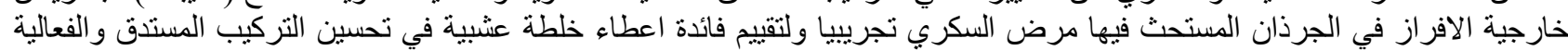

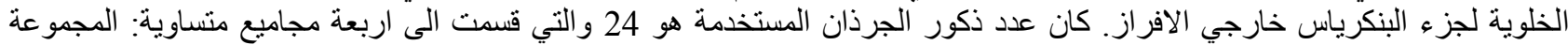

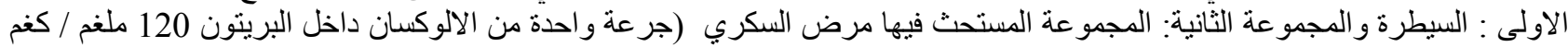

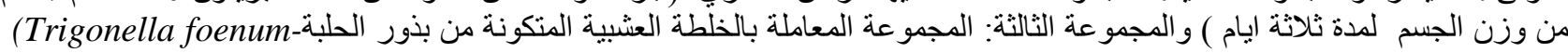

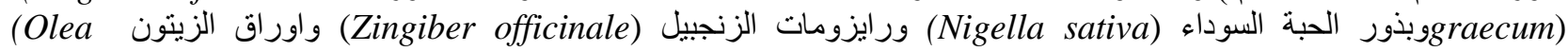
و europeae)

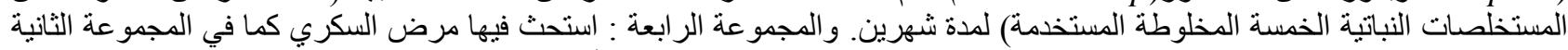

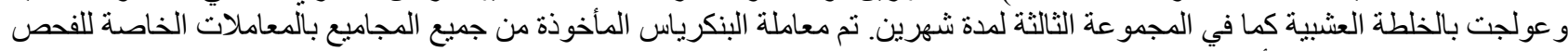

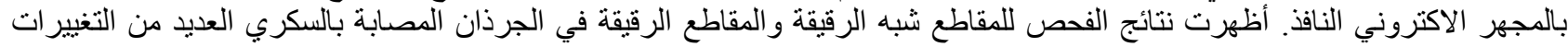

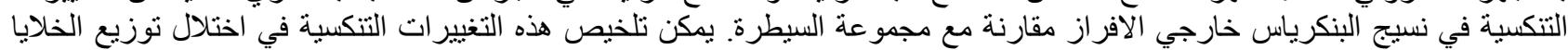

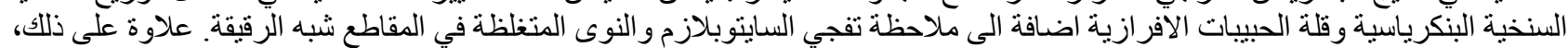

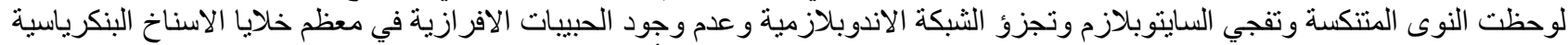

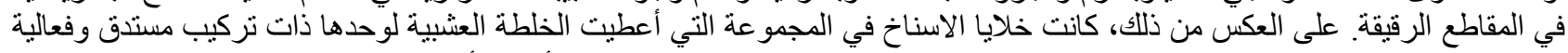

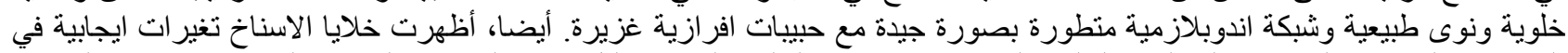

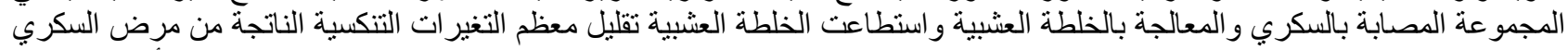

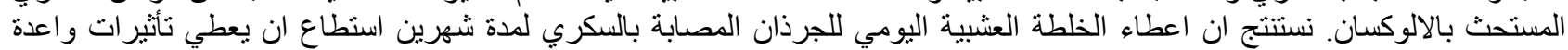

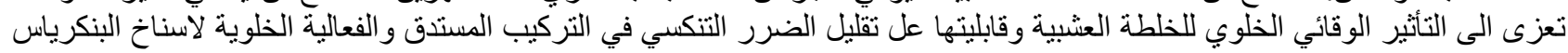

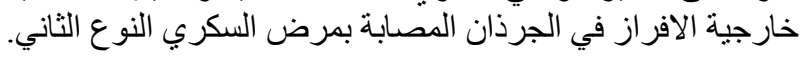

الكلمات المفتاحية: مرض السكري، البنكرياس خارجية الافراز، خلطة عشبية، المجر الالكتروني النافذ، التركيب المستدق. 